\title{
Control and Implementation of Dual-Stator-Winding Induction Generator for Variable Frequency AC-Generating System
}

\author{
Feifei $\mathrm{Bu}^{\dagger}$, Yuwen $\mathrm{Hu}^{*}$, Wenxin Huang ${ }^{*}$, and Kai Shi ${ }^{*}$ \\ $\dagger^{*}$ Key Laboratory of New Energy Generation and Power Conversion of Jiangsu Province, College of Automation \\ Engineering, Nanjing University of Aeronautics and Astronautics, Nanjing, China
}

\begin{abstract}
This paper presents the control and implementation of the dual-stator-winding induction generator for variable frequency AC (VFAC) generating system. This generator has two sets of stator windings embedded into the stator slots. The power winding produces the VFAC power to feed the loads, and the control winding is connected to the static excitation controller to control the generator for output voltage regulation with speed and load variations. On the basis of the idea of power balance, an instantaneous slip frequency control (ISFC) strategy using the information of both the output voltage and the output power is used in this system. A series of experiments is carried out on a $15 \mathrm{~kW}$ prototype for verification. Results show that the system has good static and dynamic performance in a wide speed range, which demonstrates that the ISFC strategy is suitable for this system.
\end{abstract}

Key words: Dual-stator windings, Induction generator, Instantaneous slip frequency control (ISFC), Power balance, Stand-alone power system, Static and dynamic performance, Static excitation controller (SEC), Variable frequency AC (VFAC)

\section{INTRODUCTION}

In recent years, stand-alone power systems, such as airborne and vehicle power systems, have been rapidly developing and putting forward high-power and high-performance demands. According to published literature, in addition to high-voltage DC power systems, variable frequency AC (VFAC) and hybrid power systems are also popular solutions because their use will not only reduce system weight, volume, and cost but also improve overall system efficiency [1]-[4]. For instance, both $115 \mathrm{~V} / 360 \mathrm{~Hz}$ to $800 \mathrm{~Hz} \mathrm{AC}$ and $270 \mathrm{~V} \mathrm{DC}$ power systems are used in large civil airplanes, such as the A380 and B787. Some new types of tanks, ships, and vehicles also take advantage of VFAC and high-voltage DC power systems [1]-[4].

A synchronous generator ( $\mathrm{SG}$ ) with a brushless exciter is widely used in stand-alone power systems. However, the

Manuscript received Sep. 30, 2011; revised Jul. 10, 2013

Recommended for publication by Associate Editor Jang-Mok Kim.

${ }^{\dagger}$ Corresponding Author: bufeifei1984@163.com

Tel: +86-25-84890382, Fax: +86-25-84892867

*Key Laboratory of New Energy Generation and Power Conversion of Jiangsu Province, Department of Electrical Engineering, College of Automation Engineering, Nanjing University of Aeronautics and Astronautics, China configuration of the SG system is relatively complicated, with its dynamic performance requiring further improvement [5]. The squirrel-cage induction generator (IG) has many advantages, such as being brushless, needing low-maintenance demands, and having inherent overload protection capability. The IG has attracted a great deal of interest in stand-alone power systems [4]-[6]. The reactive power consumption and poor voltage regulation with variations in speed and load are the main limitations of the widespread application of IG. Given the advancements in static power converters, many schemes have been proposed to solve these problems. Variable reactive power has been obtained by connecting a pulse width modulation voltage source inverter in series or in parallel with the load, which facilitated the control of the output voltage for IG systems. However, most of these schemes simultaneously inject harmonics into the load current and induce output voltage ripples [5]-[12].

To regulate the output voltage effectively and to eliminate/decrease the harmonics arising from the power switches, a dual-stator-winding induction generator (DWIG) with a static excitation controller (SEC) has been proposed [8], [9]. In this generator, the two sets of the stator windings have no physical connection but only an electromagnetic link, which 


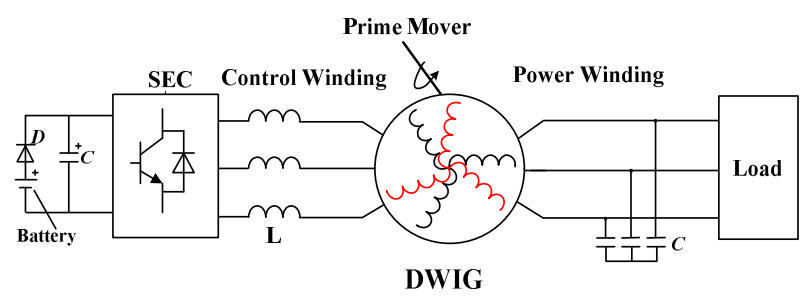

Fig. 1. Dual-stator-winding induction generator VFAC power system.

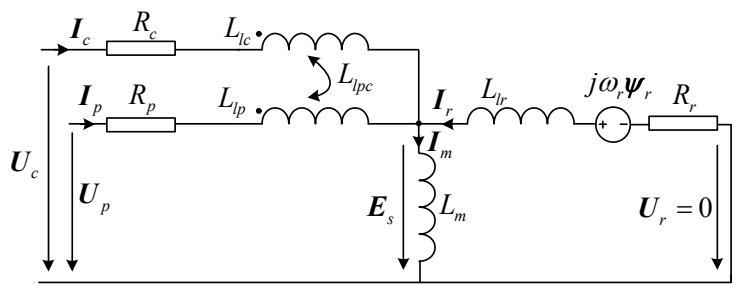

Fig. 2. Equivalent circuit of DWIG in a stationary reference frame.

restricts the influence of the inverter-induced harmonics on the load current and voltage. Nevertheless, this generator allows independent control of the active and reactive power [9], [10], thus making it suitable for stand-alone power systems with high-performance requirements. The optimal design methods and control strategies of the DWIG are thoroughly investigated [8]-[12] for the applications of constant-frequency AC power systems, high-voltage DC power systems, and wind power generation. The VFAC power systems based on the DWIG are recently considered to achieve improvements in terms of performance and capacity in the stand-alone power systems of aircrafts and military vehicles. In [13], the correctness and feasibility of the DWIG VFAC generating system is explored preliminarily; however, only some brief introductions of this system are given, and many important details, particularly the control strategy and its implementation, are not included.

The present paper fully investigates the control strategy for the DWIG VAFC generating system and presents an implementation strategy. An instantaneous slip frequency control (ISFC) strategy with information on both the output voltage and the output power is established by using the idea of power balance. The no-speed sensor method and the voltage buildup process for this ISFC strategy are also studied. This ISFC strategy is different from the control schemes that use current control with complex flux or voltage orientations for DWIG systems proposed in [8]-[12]. The experimental results from a $15 \mathrm{~kW}$ prototype are shown for verification.

\section{DWIG VFAC POWER SYSTEM}

Figure 1 shows the DWIG VFAC power system. The generator consists of a standard squirrel-cage rotor and a stator with two sets of electrically isolated three-phase star windings. On the power-winding side, the AC loads are frequency

insensitive but consume a large part of the total power. AC loads, are fed directly by VFAC power, are commonly used in heaters and illuminators in airplanes. For other loads and equipment that cannot be supplied by VFAC power directly, electric energy conversion is accomplished by using power electronic converters. This approach will reduce the total power flow through power conversion, thus simplifying the configuration of the stand-alone power systems and improving their efficiency. On the control-winding side, an SEC provides variable reactive power to the generator for output voltage regulation with speed and load changes. The two sets of stator windings have the same poles and share the same working frequency. Given that no electrical connection exists between the two sets of stator windings, the electromagnetic compatibility of this generating system is improved [9].

In advanced airplanes, as well as ships and other vehicles, computers and high-performance equipment are gradually being used along with heaters and illuminators. These computers and high-performance equipment set higher demands on the static and dynamic performance of the stand-alone power systems. Therefore, the performance of this DWIG VFAC power system should be considered.

\section{MODEL OF THE DWIG}

When the parameters on both the rotor and control winding are transformed to the power winding, an equivalent circuit of the DWIG in the stationary reference frame is provided (Fig. 2). The dynamic model of this generator is expressed as follows.

The voltage equations:

$$
\left[\begin{array}{l}
\boldsymbol{U}_{p} \\
\boldsymbol{U}_{c} \\
\boldsymbol{U}_{r}
\end{array}\right]=\left[\begin{array}{lll}
R_{p} & 0 & 0 \\
0 & R_{c} & 0 \\
0 & 0 & R_{r}
\end{array}\right]\left[\begin{array}{l}
\boldsymbol{I}_{p} \\
\boldsymbol{I}_{c} \\
\boldsymbol{I}_{r}
\end{array}\right]+\boldsymbol{p}\left[\begin{array}{l}
\psi_{p} \\
\boldsymbol{\psi}_{c} \\
\boldsymbol{\psi}_{r}
\end{array}\right]+\left[\begin{array}{c}
0 \\
0 \\
-j \omega_{r} \psi_{r}
\end{array}\right]
$$

where,

$$
\begin{aligned}
{\left[\begin{array}{l}
\boldsymbol{\psi}_{p} \\
\boldsymbol{\psi}_{c} \\
\boldsymbol{\psi}_{r}
\end{array}\right]=} & {\left[\begin{array}{ccc}
L_{p} & L_{l p c} & L_{m} \\
L_{l p c} & L_{c} & L_{m} \\
L_{m} & L_{m} & L_{r}
\end{array}\right]\left[\begin{array}{l}
\boldsymbol{I}_{p} \\
\boldsymbol{I}_{c} \\
\boldsymbol{I}_{r}
\end{array}\right] . } \\
& \left\{\begin{array}{l}
L_{p}=L_{m}+L_{l p} \\
L_{c}=L_{m}+L_{l c} \\
L_{r}=L_{m}+L_{l r}
\end{array}\right.
\end{aligned}
$$

The symbols in (1), (2), and (3) are defined as follows:

$\boldsymbol{U}_{p}, \boldsymbol{U}_{c}, \boldsymbol{U}_{r}$

$\boldsymbol{I}_{p}, \boldsymbol{I}_{c}, \boldsymbol{I}_{r}$

$\psi_{p}, \psi_{c}, \psi_{r}$

$R_{p}, R_{c}, R_{r}$
Voltage vectors of the power winding, the control winding, and the rotor;

Current vectors of the power winding, the control winding, and the rotor;

Flux vectors of the power winding, the control winding, and the rotor;

Resistance of the power winding, the control winding, and the rotor; 


$\begin{array}{ll}L_{l p}, L_{l c}, L_{l r} & \begin{array}{l}\text { Leakage inductance of the power winding, } \\ \text { the control winding, and the rotor; }\end{array} \\ L_{l p c} & \begin{array}{l}\text { Mutual leakage inductance between the } \\ \text { power winding and the control winding; }\end{array} \\ L_{m} & \text { Magnetizing inductance; } \\ \boldsymbol{p} & \text { Derivative } d / d t \\ \omega_{r} & \text { Rotor angular speed. }\end{array}$

\section{INSTANTANEOUS SLIP FREQUENCY CONTROL STRATEGY FOR THE DWIG VFAC POWER SYSTEM}

\section{A. Brief introduction to the idea of power balance}

The primary reason for output voltage variation in generating systems is power imbalance. If the input electromagnetic power is greater than the output load power, the output voltage will increase; otherwise, the output voltage will decrease. Consequently, to keep the output voltage constant, the electromagnetic power should equal the load power if the loss is to be ignored [5], [6]:

$$
T_{e} \omega_{r}=P_{o},
$$

where $T_{e}$ is the electromagnetic torque, and $P_{o}$ is the load power.

Changes in speed and load will result in output voltage variations. In general, the entire generating system has a relatively large rotating inertia, which means that the mechanical time constant is greater than the electrical time constant. When compared with the mechanical variations of the rotor speed, the electrical parameters, such as voltage and current, can change at a much faster rate. Therefore, when the load varies, the rotor speed can be assumed to be static. A control strategy must be competent for rotor speed variations to be capable of keeping the output voltage constant under a load step change. Therefore, the main focus of this paper is on the control strategy of load variations, particularly of load step changes.

\section{B. ISFC strategy for the DWIG}

When a load has a step change, the output current varies correspondingly, which leads to the output power changing abruptly as well. According to (4), the electromagnetic torque $T_{e}$ can be used to balance the input and output power to eliminate output voltage variations.

As analyzed earlier, $\omega_{r}$ can be viewed as a constant when the load changes. Thus, Eq. (5) can be obtained through the differentiation of (4).

$$
\frac{d T_{e}}{d t}=\frac{1}{\omega_{r}} \frac{d P_{o}}{d t}
$$

Equation (5) implies that to keep the output voltage stable under a load step change, the changing rate of the electromagnetic torque $T_{e}$ should be proportional to that of the output power $P_{o}$. Therefore, $T_{e}$ should be controlled to follow the change in $P_{o}$. The faster the $T_{e}$ changes, the more stable the output voltage will be.

For an induction machine, the electromagnetic torque $T_{e}$ is is closely related to the slip frequency $\omega_{\text {slip }}$ [14]. Thus, the fast regulation of $T_{e}$ can be accomplished by a quick change of $\omega_{\text {slip }}$ to balance the input and output power and to keep the output voltage constant with good dynamic performance.

For IGs, the air-gap flux is important to the electromechanical energy conversion and to the output voltage regulation. The air-gap flux can be controlled by the ratio of the amplitude and frequency of stator voltage $(\mathrm{V} / \mathrm{f})$. Two sets of stator windings share the same air-gap flux in the proposed DWIG system. Therefore, any change in the control winding flux will cause a change in the air-gap flux, which can regulate the amplitude of the output AC voltage.

Fig. 3 shows a schematic diagram of the ISFC strategy for the DWIG VFAC power system. On the basis of the information of both the output voltage and the output power, when the load or rotor speed changes, the slip frequency $\omega_{\text {slip }}$ and the air-gap flux amplitude $|\phi|$ are regulated by using the voltage vectors to guarantee that the output $\mathrm{AC}$ voltage is stable.

\section{Implementation of the ISFC strategy for the DWIG VFAC power system}

From the above analysis, the key point of the ISFC strategy is to regulate properly the slip frequency and the air-gap flux amplitude when changes in the speed and load are apparent. In the DWIG, the SEC is connected to the control winding to provide variable reactive power. The regulation of $\omega_{\text {slip }}$ and $|\phi|$ is implemented by the control of the amplitude and frequency of the voltage inverted by the SEC. Fig. 4 shows the ISFC strategy for the DWIG VFAC power system.

During sudden changes in the load, $\omega_{\text {slip }}$ should be controlled fast enough to follow the output power change to guarantee that the output voltage has good dynamic performance. This paper introduces a feed-forward controller based on a proportional $(\mathrm{P})$ regulator. Considering the power loss of the SEC and the calculation errors of the feed-forward controller, the DC bus voltage of the SEC $U_{c d c}$ varies. Therefore, $U_{c d c}$ must be kept stable to ensure the normal operation of the SEC. The errors in $U_{c d c}$ are also used to control $\omega_{\text {slip }}$ through a PI regulator. Thus, the command value of the slip frequency $\omega_{\text {slip }}^{*}$ can be given as

$$
\omega_{s l i p}^{*}=K_{p 1} P_{o}+K_{p 2}\left(U_{c d c}^{*}-U_{c d c}\right)+K_{i 2} \int\left(U_{c d c}^{*}-U_{c d c}\right) d t
$$

where $K_{p 1}$ and $K_{p 2}$ are the proportional gains; $K_{i 2}$ is the 


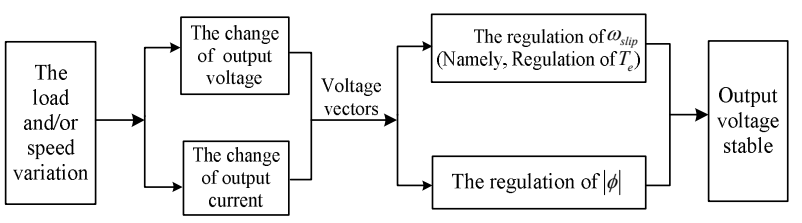

Fig. 3. Schematic of the slip frequency control strategy for the DWIG VFAC system.

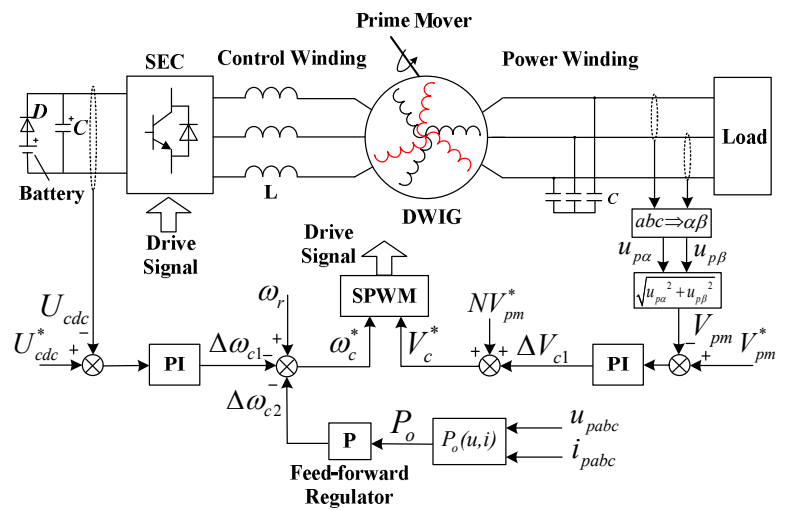

Fig. 4. Variable frequency $\mathrm{AC}$ power system of a dual-stator-winding induction generator on the basis of the ISFC strategy.

integral gain; $U_{c d c}^{*}$ is the command value of the DC bus voltage of the SEC; the output power $P_{o}$ can be obtained according to the instantaneous values of the output voltages $u_{p a}, u_{p b}$, and $u_{p c}$ and the output currents $i_{p a}, i_{p b}$, and $i_{p c}$.

When the rotating speed of the air-gap flux is less than the rotor speed, the DWIG enters the generating mode. Therefore, the command frequency $\omega_{c}^{*}$ of the voltage inverted by the SEC can be expressed as

$$
\omega_{c}^{*}=\omega_{r}-\omega_{s l i p}^{*}
$$

Considering that the DWIG operates in the constant power region, the amplitude of the voltage inverted by the SEC should be set as the constant value to realize the flux-weakening control. Considering the voltage drop of the filter inductance connected between the SEC and the control winding, the error of $V_{p m}$ must be introduced to regulate the command amplitude of the voltage inverted by the SEC by using a PI regulator, which yields

$$
V_{c}^{*}=V_{c 0}+K_{p 3}\left(V_{p m}^{*}-V_{p m}\right)+K_{i 3} \int\left(V_{p m}^{*}-V_{p m}\right) d t,
$$

where $V_{c}^{*}$ is the command amplitude of the voltage inverted by the SEC; $K_{p 3}$ and $K_{i 3}$ are the proportional and integral gains, respectively; $V_{p m}^{*}$ is the command amplitude of the output $\mathrm{AC}$ voltage; $V_{c 0}$ is the constant value, which can be written as

$$
V_{c 0}=N V_{p m}^{*},
$$

where $N$ is the turns ratio of the control winding to the power winding.

According to the command values of the amplitude and frequency of the voltage inverted by the SEC, $V_{c}^{*}$, and $\omega_{c}^{*}$, a proper modulation method is selected to generate the control signals to drive the power switches, such as sinusoidal pulsewidth modulation and space vector modulation.

\section{Determination of the command frequency $\omega_{c}^{*}$ in the ISFC} strategy

To reduce the speed sensor, an increment PI regulator is employed in the ISFC strategy to calculate the command frequency $\omega_{c}^{*}$.

From (7), the increment of $\omega_{c}^{*}$ between the two adjacent control periods can be described as follows:

$$
\Delta \omega_{c}^{*}(k)=\omega_{c}^{*}(k)-\omega_{c}^{*}(k-1)=\Delta \omega_{r}(k)-\Delta \omega_{s l i p}^{*}(k),
$$

where $\Delta \omega_{c}^{*}(k), \Delta \omega_{r}(k)$, and $\Delta \omega_{s l i p}^{*}(k)$ are the increments of $\omega_{c}^{*}, \omega_{r}$, and $\omega_{s l i p}^{*}$ between the two adjacent control periods, respectively. $k$ and $k-1$ donate the current and the former control periods, respectively.

Given that the control period is smaller than the mechanical time constant, $\omega_{r}$ remains unchanged between the two adjacent control periods. Thus, $\Delta \omega_{r}(k)$ can be ignored, and Eq. (10) is rewritten as

$$
\Delta \omega_{c}^{*}(k)=-\Delta \omega_{\text {slip }}^{*}(k) .
$$

On the basis of $(6), \Delta \omega_{\text {slip }}^{*}(k)$ can be expressed as

$$
\begin{aligned}
\Delta \omega_{s l i p}^{*}(k) & =\omega_{\text {slip }}^{*}(k)-\omega_{\text {slip }}^{*}(k-1) \\
& =K_{p 1} \Delta P_{o}(k)+K_{p 2}\left[e_{d c}(k)-e_{d c}(k-1)\right]+K_{i 2} e_{d c}(k)
\end{aligned},
$$

where $\Delta P_{o}(k)$ is the increment of $P_{o}$ between the current and the former control periods. $e_{d c}(k)$ and $e_{d c}(k-1)$ represent the errors of $U_{c d c}$ in the current and former control periods, respectively.

When $\Delta \omega_{s l i p}^{*}(k)$ is obtained, the command frequency of the voltage inverted by the SEC in the current control period can be expressed as

$$
\omega_{c}^{*}(k)=\omega_{c}^{*}(k-1)-\Delta \omega_{s l i p}^{*}(k) .
$$

Fig. 5 illustrates the determination of the command frequency by using an increment PI regulator. On the basis of this method, no-speed sensor is required in the ISFC strategy for the DWIG VFAC power system.

\section{E. Voltage buildup process for the ISFC strategy}




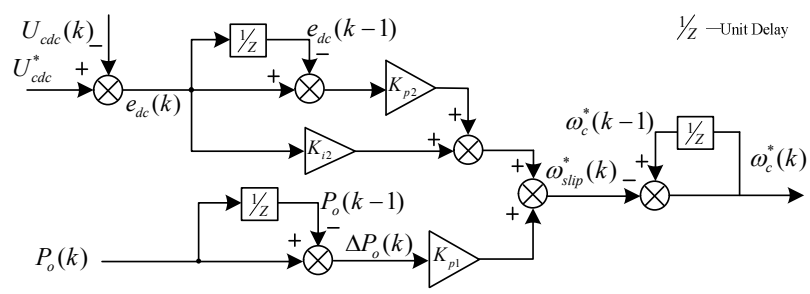

Fig. 5. Determination of the command frequency by using the increment PI regulator.

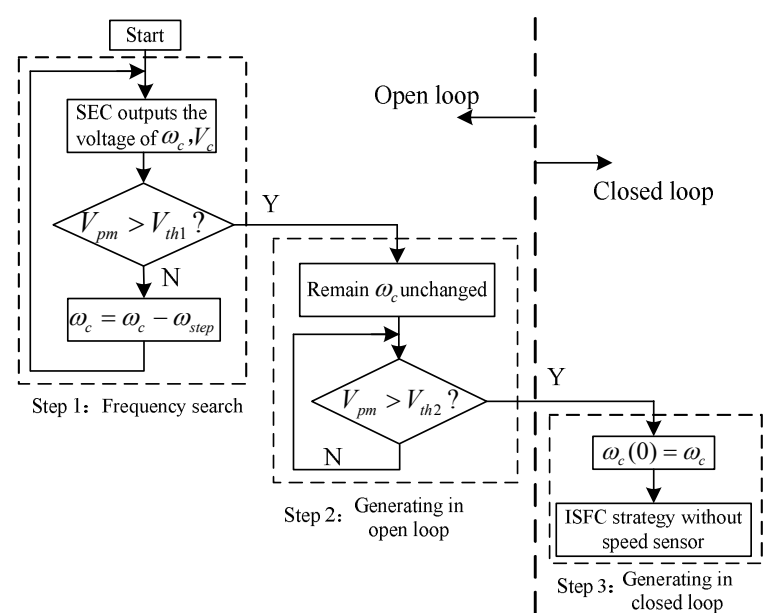

Fig. 6. Sketch map of the voltage buildup process for the DWIG VFAC power system.

In the DWIG, two sets of stator windings are present, and an SEC is connected to the control winding, which results in increased complexity of the voltage buildup process when compared with a traditional IG. Considering that a no-speed sensor exists in this system, the entire voltage buildup process is divided into three steps, namely, frequency search, generation in an open loop, and generation in a closed loop. The voltage buildup process for this system is shown in Fig. 6.

To achieve DWIG generation, the synchronous speed should be less than the rotor speed. The SEC outputs a voltage with constant amplitude and a variable frequency by connecting a $24 \mathrm{~V}$ battery to the DC bus of the SEC through a diode. The rotor speed is unknown. Therefore, the frequency of the voltage decreases gradually from a high value to search for the correct value until the DWIG enters the generating mode and $V_{p m}$ is greater than the threshold $V_{t h 1}$. When the frequency search is complete, the voltage inverted by the SEC keeps the last frequency unchanged. Both the DC bus voltage of the SEC and the output $\mathrm{AC}$ voltage continue to grow because the DWIG operates in the generating mode. The ISFC strategy is put into operation when $V_{p m}$ reaches a higher threshold $V_{t h 2}$. After the system goes into a closed loop, the DC bus voltage of the SEC and the output AC voltage increase to their respective command values under the control of the ISFC strategy.

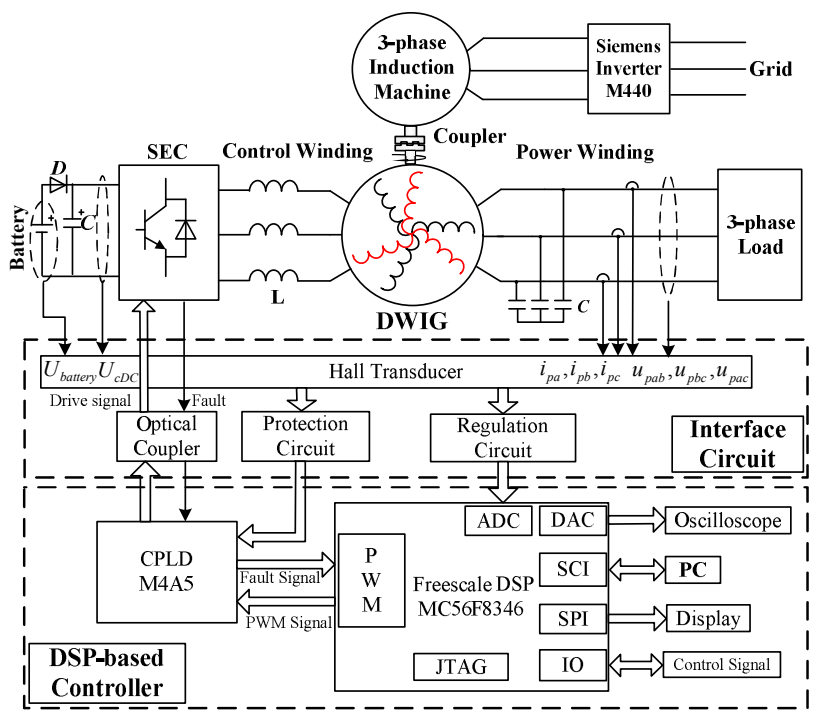

Fig. 7. DSP-based configuration for the DWIG VFAC power system.

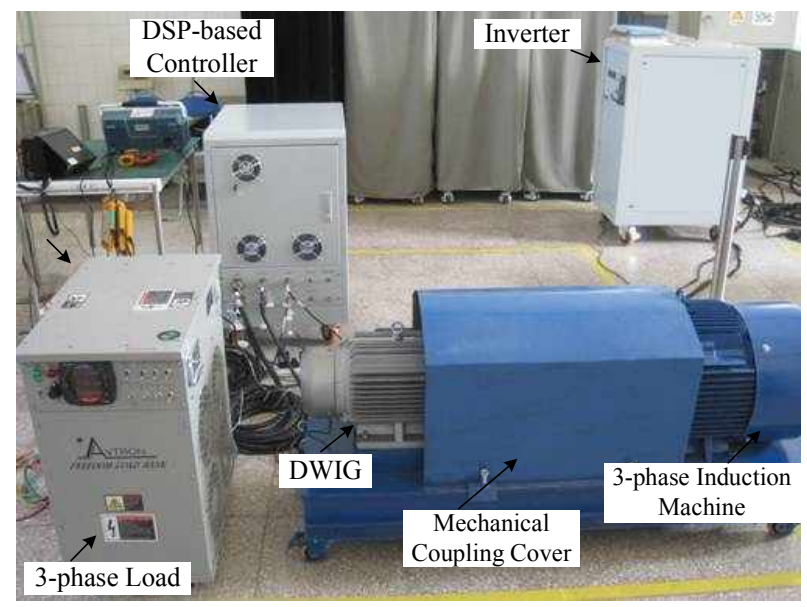

Fig. 8. Prototype of the $15 \mathrm{~kW}$ DWIG VFAC power system.

The battery is automatically removed from the system when the DC bus voltage is greater than $24 \mathrm{~V}$ because the diode is being linked in a series between the battery and the DC bus of the SEC. As a result, the capacity of the battery is small. The last frequency in the open loop shown in Fig. 6 is used as the initial value of $\omega_{c}^{*}(k)$ in (13) (i.e., $\left.\omega_{c}(0)\right)$ of the increment PI regulator for the command frequency calculation.

\section{EXPERIMENTAL RESULTS AND DISCUSSION}

A $15 \mathrm{~kW}$ prototype has been developed (see Figs. 7 and 8) to verify the aforementioned ISFC strategy for the DWIG VFAC power system. A DSP (Freescale MC56F8346) is employed as controller to implement the ISFC strategy. The SEC consists of a three-leg Mitsubishi intelligent power module. The prime mover is simulated by an $18 \mathrm{~kW}$ three-phase induction machine driven by a Siemens M440 inverter. The load is an Avtron three-phase resistive load. The 


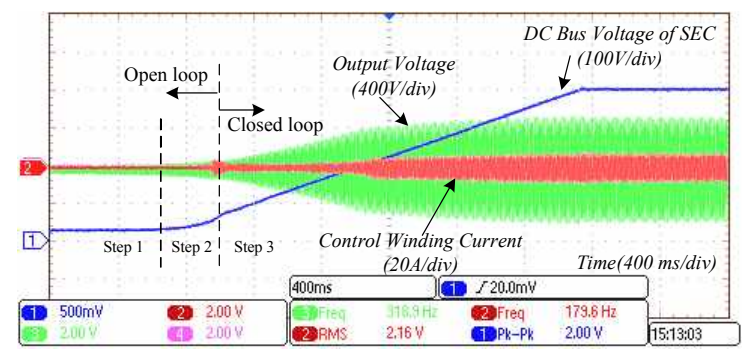

Fig. 9. Experimental results for the voltage buildup process at the rated speed of $2700 \mathrm{rpm}$.

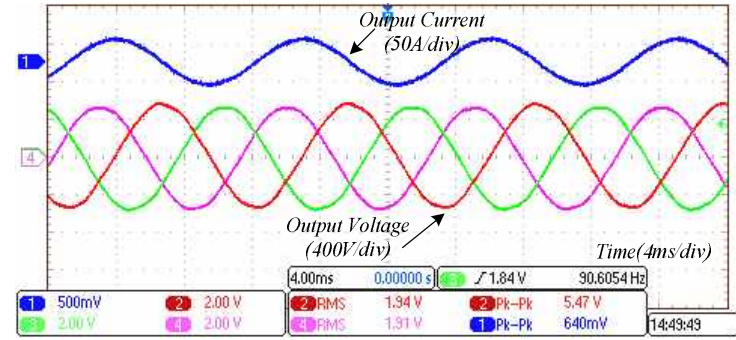

Fig. 10. Experimental results for the steady state at speed of $2700 \mathrm{rpm}$ with the rated load.

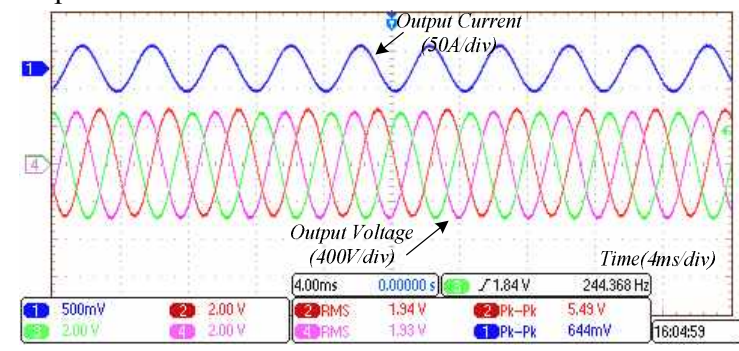

Fig. 11. Experimental results for the steady state at speed of $7500 \mathrm{rpm}$ with the rated load.

TABLE I

EXPERIMENTAL Results FOR THE STEAdy State.

\begin{tabular}{|c|c|c|c|}
$\begin{array}{r}\text { Output } \\
\text { voltage }\end{array}$ & $\begin{array}{c}\text { Amplitude of } \\
\text { output line } \\
\text { voltage (V) }\end{array}$ & $\begin{array}{c}\text { RMS of } \\
\text { output line } \\
\text { voltage (V) }\end{array}$ & $\begin{array}{c}\text { THD of } \\
\text { output line } \\
\text { and load }\end{array}$ \\
\hline $\begin{array}{c}2,700 \mathrm{rpm}, \\
\text { rated load }\end{array}$ & $544,545,547$ & $383,388,382$ & $<2 \%$ \\
\hline $\begin{array}{c}7,500 \mathrm{rpm}, \\
\text { rated load }\end{array}$ & $544,546,549$ & $383,388,386$ & $<2 \%$ \\
\hline
\end{tabular}

other parameters of this prototype are listed in the Appendix. A series of experiments involving the voltage buildup, the static performance, and the dynamic performance were carried out on this prototype.

\section{A. Experimental results for the voltage buildup}

The waveforms of the voltage buildup process at the rated speed of $2700 \mathrm{rpm}$ are shown in Fig. 9. To avoid overshoots in current and voltage, the practical command value in the DSP-based controller is set as a ramp. Fig. 9 shows that the output AC voltage and the DC bus voltage of the SEC grow

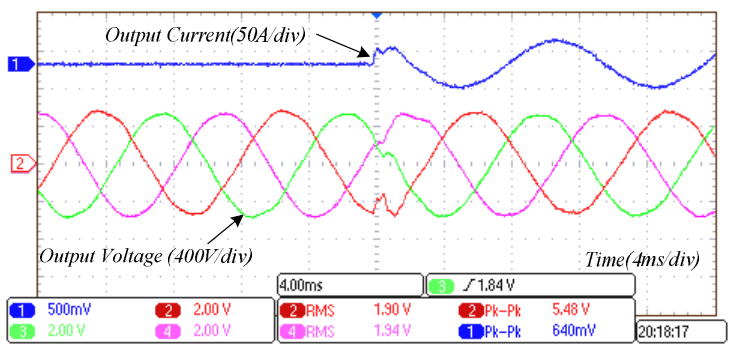

(a) Under step load of the rated load.

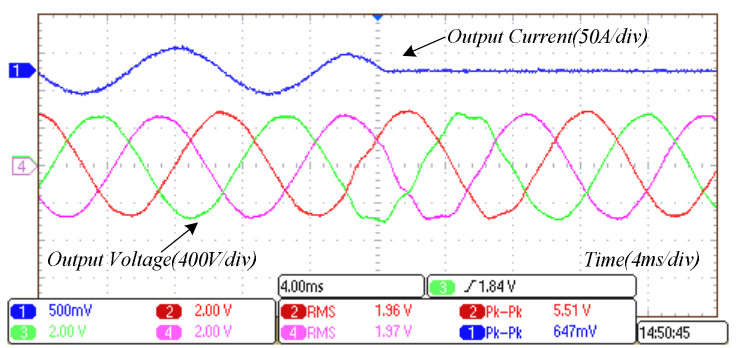

(b) Under step unload of the rated load.

Fig. 12. Experimental results for the dynamic state at speed of $2700 \mathrm{rpm}$.

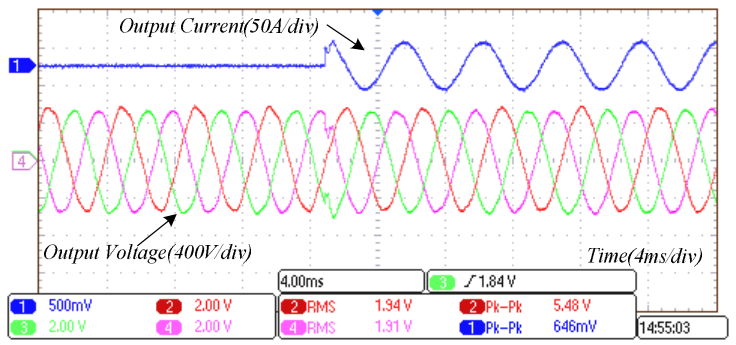

(a) Under step load of the rated load.

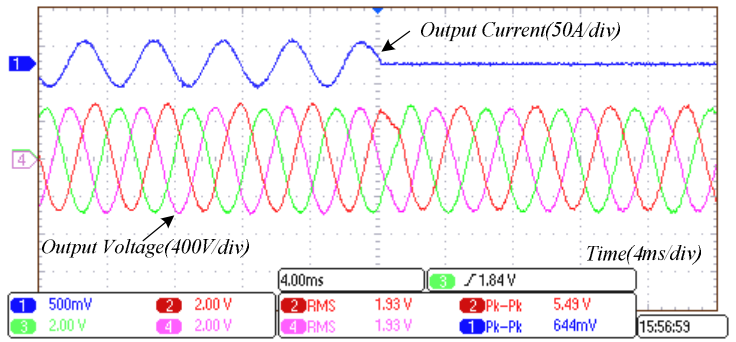

(b) Under step unload of the rated load.

Fig. 13. Experimental results for the dynamic state at speed of $7000 \mathrm{rpm}$.

to command values of $380 \mathrm{~V} \mathrm{AC}$ and $400 \mathrm{~V} \mathrm{DC}$, respectively, without overshoot. The entire voltage buildup process comprises three steps, which is consistent with the analysis in Section IV part E.

\section{B. Experimental results for the static performance}

Figs. 10 and 11 show the experimental results for the steady state at the speed of 2700 and $7500 \mathrm{rpm}$, respectively. The detailed results are presented in Table I. Figs. 10 and 11 and Table I show that the system has good static performance 


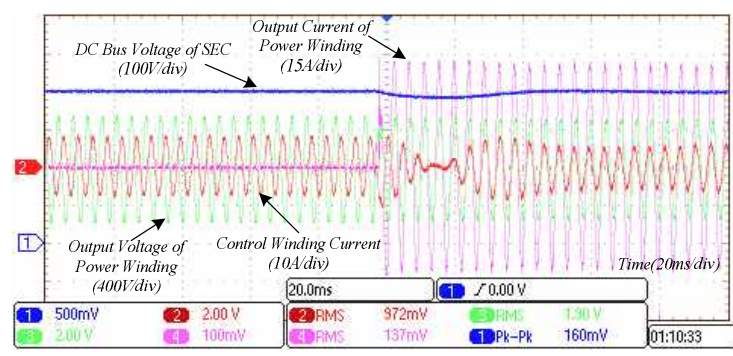

(a) Under step load of the rated power at $7000 \mathrm{rpm}$.

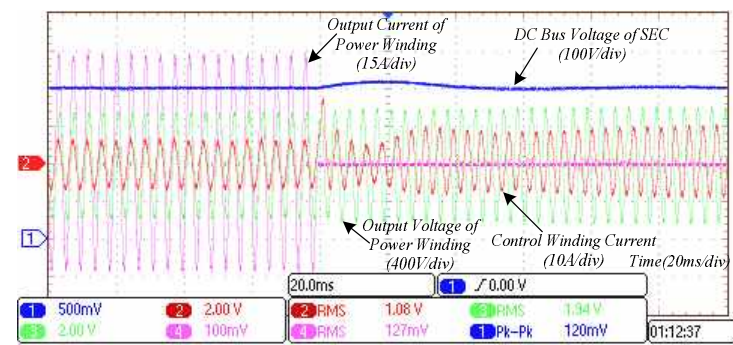

(b) Under step unload of the rated power at $7000 \mathrm{rpm}$.

Fig. 14. Experimental results for the dynamic performance of the DC bus voltage.

at low and high speeds with different loads. The three output line voltages are balanced, the static error of their RMS value is about $7 \mathrm{~V}$, and their THD is not more than $2 \%$.

\section{Experimental results for load step changes}

To test the dynamic performance of this prototype, experiments for load step changes are conducted at different speeds. Figs. 12 and 13 show the experimental results for the output voltage under step changes of the rated load at speeds of 2700 and $7000 \mathrm{rpm}$, respectively. The system is stable whether the speed is low or high. When the rated load is added and removed suddenly, the overshoot and distortion of the output $\mathrm{AC}$ voltage is small and can revert to the command value quickly. These results illustrate that this system has fast dynamic performance under load step changes. The regulation time is less than $10 \mathrm{~ms}$.

Fig. 14 gives the experimental results for the DC bus voltage at the speed of $7000 \mathrm{rpm}$ under step changes of the rated load of the power winding. The results show that the DC bus voltage also has good dynamic performance.

\section{Experimental results for rotor speed variations}

Figs. 12, 13, and 14 verify that the system using the ISFC strategy has good dynamic performance under load step changes. To test whether the system has the ability to keep the output voltage constant with speed variations, experiments have been conducted. The waveforms are shown in Figs. 15 and 16. When the speed is increased from 6500 $\mathrm{rpm}$ to $7500 \mathrm{rpm}$ within $1 \mathrm{~s}$, both the output AC voltage and the DC bus voltage of the SEC are stable (Fig. 15). Fig. 16 shows the waveforms of the output AC voltage when the

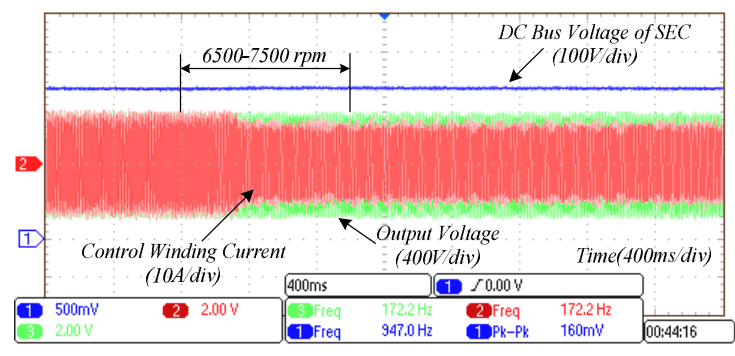

Fig. 15. Experimental results for the output voltage without load under the fast speed change from 6500 to $7500 \mathrm{rpm}$ within $1 \mathrm{~s}$.

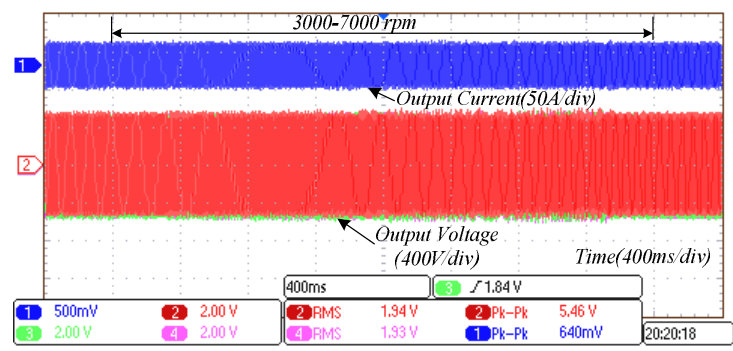

Fig. 16. Experimental results for the output voltage with the rated load under the speed increase from 3000 to $7000 \mathrm{rpm}$.

speed is increased gradually from 3000 to $7000 \mathrm{rpm}$. The output voltage remains constant under these circumstances. These results prove that this system has good performance in the presence of speed variations.

\section{CONCLUSIONS}

The paper presents the ISFC strategy and its implementation for the DWIG VFAC generating system. The principle of this ISFC strategy is analyzed based on the idea of power balance. On the basis of the information from both the output voltage and the output power, the fast control of the slip frequency is used to regulate the output voltage with speed and load variations by using voltage vectors instead of a current loop. In this ISFC strategy, the no-speed sensor is required in the entire working condition because of the increment PI regulator. As a result, a brief control structure is achieved. Experimental results show the system has good static and fast dynamic performance in a wide-speed range, and the voltage buildup method is suitable.

In addition, this system can output DC power from the DC bus of the SEC. This advantage is suitable for building a hybrid power system by using the DWIG with the ISFC strategy.

\section{APPENDIX}

The main parameters of the prototype of the $15 \mathrm{~kW}$ DWIG VFAC power system are as follows (both the rotor and the control winding are converted to the power winding):

$R_{p}=0.381 \Omega ; \quad R_{c}^{\prime}=0.587 \Omega ; R_{r}^{\prime}=0.13 \Omega ; \quad L_{l p}=1.14 \mathrm{mH} ;$ $L_{l c}^{\prime}=1.79 \mathrm{mH} \quad ; \quad L_{l r}^{\prime}=1.53 \mathrm{mH} \quad ; \quad L_{l p c}=0.16 \mathrm{mH} \quad ;$ 
$L_{m}=39.26 \mathrm{mH}$; pole pairs, 2 ; rated power, $15 \mathrm{~kW}$; rated speed, 2,700 rev/min; speed range, 2,700 $\mathrm{rpm}$ to $8,100 \mathrm{rpm} \mathrm{(1:3);}$ rated output $\mathrm{AC}$ voltage, $380 \mathrm{~V} \mathrm{AC}(90 \mathrm{~Hz}$ to $270 \mathrm{~Hz})$; turns ratio of control winding to power winding, 1:2; excitation capacitor connected to power winding, $9.4 \mu \mathrm{F}$; $\mathrm{DC}$ bus voltage of SEC, $400 \mathrm{~V}$ DC; DC bus capacitor, $1,100 \mu \mathrm{F} / 500 \mathrm{~V}$; filter inductor, $3 \times 0.75 \mathrm{mH}$; and voltage of battery, $24 \mathrm{~V}$ DC.

\section{ACKNOWLEDGMENTS}

This work is supported by the Funding of Jiangsu Innovation Program for Graduate Education under Grant CXZZ11_0209, the National Natural Science Foundation of China under Grant 51277095, the Aviation Science Foundation of China under Grant 2012ZC52048, and the National High-tech Research and Development Program (863 Program) of China under Grant 2008AA05Z411.

\section{REFERENCES}

[1] K. Emadi and M. Ehsani, "Aircraft power systems: technology, state of the art, and future trends," IEEE $A \& E$ Systems Magazine, Vol. 15, No.1, pp.28-32, Jan. 2000.

[2] Jie Chang, "Outlook of roles and necessities of power electronics for VF-power system of future large aircraft," 2008 International Conference on Electrical Machines and Systems, ICEMS 2008, pp. 1190-1195, Oct. 2008.

[3] W. Ma, "AC-DC power integration techniques," Chinese Engineering Science, Vol.4, No.12, pp. 53-59, Dec. 2002.

[4] T. Ahmed, K. Nishida, and M. Nakaoka, "AC and DC applications of induction generator excited by static VAR compensator," Journal of Power Electronics, Vol. 4, No. 3, pp.169-179, 2004

[5] Y. Hu, W. Huang, and Y. Li, "A novel instantaneous torque control scheme for induction generator systems," IEEE Trans. Energy Convers., Vol. 25, No. 3, pp. 795-803, Sept. 2010.

[6] Y. Hu, L. Zhang,L. Zhang, W. Huang, and F. Bu, "A Fault-Tolerant Induction Generator System Based on Instantaneous Torque Control (ITC)," IEEE Trans. Energy Convers., Vol. 25, No. 2, pp. 412-421, Jun. 2010.

[7] L. Tang, and M.F. Rahman, "A new direct torque control strategy for flux and torque ripple reduction for induction motors drive by using space vector modulation," 2001 IEEE 32nd Annual Power Electronics Specialists Conference, PESC 2001, pp. 1440-1445, Jun. 2001.

[8] O. Ojo and I. E. Davidson, "PWM-VSI inverter-assisted stand-alone dual stator winding induction generator," IEEE Trans. Ind. Appl., Vol. 36, No. 6, pp. 1604-1611, Nov. 2000

[9] D. Wang, W. Ma, F. Xiao, B. Zhang, D. Liu, and A. Hu "A novel stand-alone dual stator-winding induction generator with static excitation regulation," IEEE Trans. Energy Convers., Vol. 20, No. 4, pp. 826-835, Dec. 2005.

[10] Y. Li, Y. Hu, W. Huang, L. Liu, and Y. Zhang, "The capacity optimization for the static excitation controller of the dual-stator-winding induction generator operating in a wide speed range," IEEE Trans. Ind. Electron., Vol. 56, No. 2, pp. 530-541, Feb. 2009.

[11] F. Bu, W. Huang, Y. Hu, and K. Shi, "An excitation-capacitor-optimized dual stator-winding induction generator with the static excitation controller for wind power application," IEEE Trans. Energy Convers., Vol. 26, No. 1, pp. 122-131, Mar. 2011.

[12] K. Shi, W. Huang, Y. Hu, and F. Bu, "An indirect-field-oriented dual stator-winding induction generator for the wind power system applications," 2009 IEEE World Non-Grid-Connected Wind Power and Energy Conference, pp. 152-156, Sep. 2009.

[13] F. Bu, W. Huang, Y. Hu, J. Shi, and K. Shi, "A stand-alone dual stator-winding induction generator variable frequency AC power system," IEEE Trans. Power Electron., Vol. 27, No. 1, pp. 10-13, Jan. 2012.

[14] P. C. Krause, Analysis of Electric Machinery, New York: McGraw-Hill, 1986.

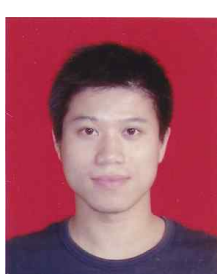

Feifei Bu was born in Maanshan, Anhui Province, China, in 1984. He received his BS in Electrical Engineering from the Anhui University of Technology, Maanshan, China, in 2006 . He is currently pursuing his $\mathrm{PhD}$. at the Nanjing University of Aeronautics and Astronautics (NUAA), Nanjing, China. His current research interests include stand-alone power systems, wind power generation, control and optimized designs for generator systems, and variable-speed drives.

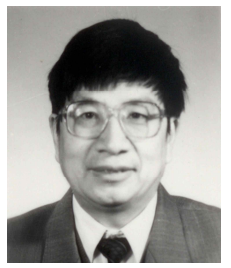

Yuwen Hu was born in Zhangshu, Jiangxi Province, China, in 1944. He received his BS from Jianxi University (now Nanchang University), Nanchang, China, in 1966, and his MS from the Nanjing Aeronautical Institute (now the Nanjing University of Aeronautics and Astronautics, NUAA), Nanjing, China, in 1981. He worked at the Jiangxi Machine Tools Factory from 1967 to 1977. He later joined NUAA. From 1986 to 1987, he was a visiting scholar at Kyushu University, Fukuoka, Japan. From 1995 to 1996 and from 2001 to 2002, he was a visiting scholar at the University of New South Wales, Sydney, Australia. He is currently a professor at NUAA. His research interests include power electronics, electrical machines, and motion control systems.

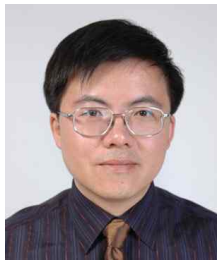

Wenxin Huang was born in Dongtai, Jiangsu Province, China, in 1966. He received his BS from the Southeast University, Nanjing, China, in 1988 and his MS and PhD from the Nanjing University of Aeronautics and Astronautics (NUAA), Nanjing, China, in 1994 and 2002, respectively. He joined the faculty of the College of Automation Engineering, NUAA, in 2003 and is currently a professor. His research interests include the design and control of electrical machine systems.

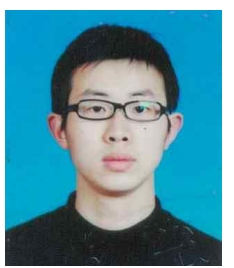

Kai Shi was born in Zhangjiagang, Jiangsu Province, China, in 1980. He received his BS and MS in Power Electronics and Drives from Jiangsu University, Zhenjiang, China, in 2002 and 2005, respectively. $\mathrm{He}$ is currently pursuing his $\mathrm{PhD}$ at the Nanjing University of Aeronautics and Astronautics (NUAA), Nanjing, China. His current research interests include control and design for wind power generation systems. 